\title{
Study of Bacterial Diversity of Mangroves Rhizosphere
}

\author{
Nidhi Sakhia1, Sunil Prajapati², Vikram Shetty', Shreyas Bhatt², Anasuya Bhadalkar1 \\ ${ }^{1}$ Marine Bio Resource Centre (MBRC), Jamnagar, Gujarat, India \\ ${ }^{2}$ Department of Life sciences, Hemchandracharya North Gujarat University, Patan, Gujarat, India \\ Email: lahiryanasuya@gmail.com
}

Received 1 October 2015; accepted 26 December 2015; published 29 December 2015

Copyright (C 2016 by authors and Scientific Research Publishing Inc.

This work is licensed under the Creative Commons Attribution International License (CC BY).

http://creativecommons.org/licenses/by/4.0/

\section{(c) (i) Open Access}

\section{Abstract}

Microbial diversity has been an important facet of scientific research, since microbes promise a plethora of biomolecules which are otherwise not found in nature. Microbes are subjected to high level of competition for survival in the environment, and hence develop mechanisms of defense. The biomolecules produced by these microbes as part of their defense or survival mechanism, are of importance for human and animal drugs and many other industrial and environmental applications. The marine counterparts of these terrestrial microbes have yet higher potential, since the marine environment has higher biotic and abiotic stresses, leading to new molecule discovery. In the current study, a bacterial diversity study of the culturable bacteria of the mangrove rhizosphere of Avicennia marina has been undertaken, to understand the flora diversity. Mangroves are unique ecosystems which are under a combination of marine and terrestrial influence. Mangroves are seaward, inland and also found in creek areas. This diversity in their habitat, leads them to produce variable root exudates, which support the growth of different types of organisms. This study has revealed that certain species are dominant in these ecosystems irrespective of the biotic and abiotic stresses, whereas certain species appear only at neutral $\mathrm{pH}$. The study will help select organisms for further biomolecule discovery programs, based on their environment of isolation and other growth parameters.

\section{Keywords}

Rhizosphere, Mangroves, Bacteria, Microbial Diversity, 16S rRNA Sequencing

\section{Introduction}

Mangroves are unique coastal plants which have originated due to the tectonic land shifts because of which ter- 
restrial plants got bared to the open sea with ecological and economic importance. They not only provide socio-economic benefits to local tribes, but also provide protection to coastal areas against natural disasters and facilitate the formation of land by trapping sediments [1] [2]. Around 34 major and 20 minor mangrove species belonging to about 20 genera in over 11 families have been recorded globally [3]. Mangroves constitute a significant part of tropical coastal biodiversity which occupy less than $1 \%$ of the world's surface [4] and are mainly found between the Tropic of Cancer and the Tropic of Capricorn on all continents covering an estimated $75 \%$ of the tropical coastline worldwide. Mangroves of South and Southeast Asia form the most extensive and diverse mangrove system comprising 41.4\% of global mangroves in the world [5]. Among them Indian mangroves make up $3.1 \%$ of the total global cover and are distributed along all the maritime states except the union territory of Lakshwadeep covering an area of about $4461 \mathrm{~km}^{2}$ along the $7500 \mathrm{~km}$ long Indian coastline [6]. Gujarat state, with a coastline of about $1650 \mathrm{~km}$, harbors approximately $960 \mathrm{~km}^{2}$ of mangroves [6]. Gujarat mangrove forest covers $1103 \mathrm{~km}^{2} ; 175 \mathrm{~km}^{2}$ are moderately dense and $928 \mathrm{~km}^{2}$ are open mangrove forests (FSI, 2013). Mangroves in Gujarat are mostly confined to three regions a) Indus deltaic region i.e. Kori creek and Sir Creek area, b) The Gulf of Kachchh and c) The Gulf of Khambhat.

Bacterial diversity from these ecosystems has been studied worldwide for their unique biochemical processes. The present study includes isolation, morphological characterization and identification of rhizospheric bacteria using biochemical and molecular biology techniques [7] [8]. Molecular biology techniques like 16S rRNA techniques are an important tool in final identification of bacteria sequencing this gene, and provide genus and species identification for isolates that do not fit any recognized biochemical profiles. It gives acceptable identification which otherwise according to conventional system of taxonomy is not possible [9].

\section{Materials and Methods}

\subsection{Study Area and Sample Collection}

The study was conducted at three different sites of southern part of Gulf of Kachch, Gujarat. The geographical location of collection sites are: Station 1 -Sikka (Latitude $22^{\circ} 26.406^{\prime} \mathrm{N}$ Longitude $069^{\circ} 50.029^{\prime} \mathrm{E}$ ) (coastal wetland, port activity), Station 2-Valsura (Latitude $22^{\circ} 33.578^{\prime} \mathrm{N}$ Longitude $070^{\circ} 02.502^{\prime} \mathrm{E}$ ) (coastal wetland, ship breaking activity) and Station 3-Khijadiya (Latitude $22^{\circ} 31.375^{\prime} \mathrm{N}$ Longitude $070^{\circ} 08.099^{\prime} \mathrm{E}$ ) (inland wetland, bird sanctuary) (see Figure 1). It contains about 30 - 35 ppt (parts per trillion) soil salinity and has a temperature around $26^{\circ} \mathrm{C}-30^{\circ} \mathrm{C}$. The $\mathrm{pH}$ of the three location varied from $6.0-8.0$. Avicennia marina (true mangrove plant) rhizosphere soil samples were collected carefully by sterile spatula in sterile polypropylene tubes, properly labeled. These were transported in an ice box to the laboratory and processed within $2-4 \mathrm{~h}$ of collection.

\subsection{Isolation of Bacteria}

About $1 \mathrm{~g}$ of rhizosphere soil of Avicennia marina was transferred to $50 \mathrm{~mL}$ test tube containing $10 \mathrm{~mL}$ sterile distilled water and vortexed vigorously for $10 \mathrm{~min}$. The resulting solution containing the rhizosphere bacteria was serially diluted up to $10^{-4}$ using sterile distilled water. $100 \mu \mathrm{l}$ aliquot was taken from each dilution and plated in triplicate onto Zobell's marine agar 2216 (ZB agar) (Himedia, India), MPM (Synthetic sea water media) agar medium [10] and incubated at $28^{\circ} \mathrm{C}$ for $24-96 \mathrm{~h}$. After incubation, colony counts were recorded and colonies with distinctive morphologies were selected for further studies. The isolated bacteria were purified by streak plate technique [11]. The 35 isolates obtained through this process of isolation were subjected to various biochemical tests according to "Bergey's Manual of Determinative Bacteriology" (Volume-4) and molecular techniques of identification.

\subsection{Identification of Bacterial Isolates}

\subsubsection{Morphological Characterization}

The morphological characterization of the bacterial colonies were carried out on the basis of their shape, size, colour, margin, elevation on the media and Gram staining were performed to decide the further determinative protocol.

\subsubsection{Biochemical Analysis}

The pure culture were subjected to identification by Bergey's Manual of Determinative Bacteriology (Volume-4) 


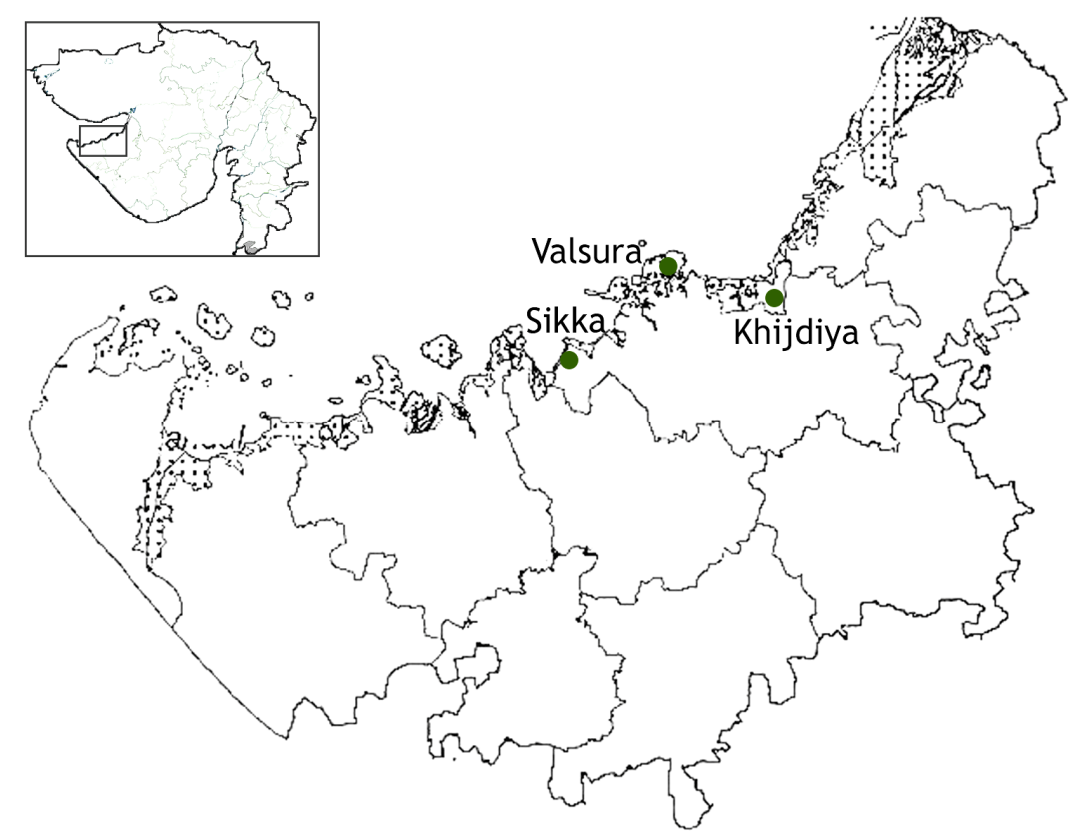

Figure 1. Sample collection sites in Gulf of Kachchh, Gujarat.

using catalase test with 3\% hydrogen peroxide, Anaerobic Test, Oxidative Fermentative (O/F test), methyl red test, Voges Proskaeur test, glucose test, sorbitol test and mannitol test.

\subsubsection{Molecular Analysis}

\section{Genomic DNA Isolation}

Culture was centrifuged at 10,000 rpm for $5 \mathrm{~min}$. Pellet was collected and resuspended by adding $9 \mathrm{ml}$ of STE buffer $(0.1 \mathrm{mM} \mathrm{NaCl}, 10 \mathrm{mM}$ Tris, $10 \mathrm{mM}$ EDTA) $1 \mathrm{ml}$ of SDS (10\% Stock Solution). The suspension was incubated at $70^{\circ} \mathrm{C}$ for $1 \mathrm{hr}$. and centrifuged at $6000 \mathrm{rpm}$ for $10 \mathrm{~min}$ at room temperature. The supernatant was collected in fresh tube and add equal volume of Phenol:Chloroform:Isoamyl alcohol (PCI mix) (25:24:1) was added and mixed slowly. The suspension was centrifuged at $6000 \mathrm{rpm}$ for $10 \mathrm{~min}$. The aqueous phase in fresh tube. Equal vol. of Chloroform: Isoamyl alcohol (24:1) and mix slowly and centrifuged at $6000 \mathrm{rpm}$ for $10 \mathrm{~min}$. The aqueous phase was collected and added double the vol. of absolute alcohol was added. The tube was subjected to overnight incubation in $-20^{\circ} \mathrm{C}$. The solution was centrifuged at $6000 \mathrm{rpm} 4^{\circ} \mathrm{C}$ for $10 \mathrm{~min}$ and the pellet was resuspended in $1 / 10^{\text {th }} \mathrm{ml}$ of $3 \mathrm{M}$ sodium acetate and $10 \mathrm{ml}$ of absolute alcohol and centrifuged at $6000 \mathrm{rpm} 4^{\circ} \mathrm{C}$ for $10 \mathrm{~min}$. The supernatant was discarded and the pellet was air dried. The pellet was dissolved in $1 \mathrm{ml}$ sterile TE buffer. The DNA quality was checked using Agarose gel electrophoresis and quantified using Nanodrop.

\section{PCR Amplification and Phylogenetic Analysis}

The 16S rRNA gene from the genomic DNA was amplified using primers $\mathrm{F}$ 5'-AGAGTTTGATCCTGG CTAG-3', R 5'-CGGTTACCTTGTTACGACTT-3' and F5'-TGGAGAGTTTGATCCTGGCTCAG-3', R 5'GGTTACCTTGTTACGACTT-3' (at Xcelris Genomics Pvt. Ltd., Ahmedabad and Junagadh Agricultural University, Junagadh). The PCR reaction mixture $(25 \mu \mathrm{l})$ comprised of bacterial DNA $(50 \mathrm{ng}), 10 \mathrm{pmol}$ each of the two oligonucleotide primers, $2.5 \mathrm{mM}$ of each deoxynucleoside triphosphate, $1.5 \mathrm{U}$ of Taq polymerase and $2.5 \mu \mathrm{l}$ of $10 \times$ buffer. The amplification was performed using following PCR cycle: the initial denaturation at $94^{\circ} \mathrm{C}$ for $5 \mathrm{~min}$, followed by 35 cycles of $94^{\circ} \mathrm{C}$ for $30 \mathrm{~s}, 60^{\circ} \mathrm{C}$ for $30 \mathrm{~s}$ and $72^{\circ} \mathrm{C}$ for $90 \mathrm{~s}$ and a final extension of $72^{\circ} \mathrm{C}$ for $10 \mathrm{~min}$. PCR product was electrophoresed on $1.5 \%$ agarose gel. PCR products varied from $1200 \mathrm{bp}$ to $1500 \mathrm{bp}$. Sequencing was performed by ABI 3730xl Genetic Analyzer 96 well capillary system.FASTA files were subjected to BLAST for further analysis [12]. A phylogenetic tree was constructed using MEGA 5.1 software. The top ten alignment matches were presented according to percent similarity and the nearest distances.

Identification utilizing GenBank database was carried out by internet-based 16S rRNA gene sequence comparison software utilizing the basic local alignment search tool with default settings. The closest species level match ( $\%$ identity) was considered the identification. 


\section{Results}

\subsection{Isolation and Enumeration of Bacteria}

The average number of culturable heterotrophic bacteria in soil samples from the three different stations was $2.41 \times 10^{8} \mathrm{CFU} / \mathrm{g}$. Among the collection station, soil sample from the Khijadiya mangroves recorded the highest bacterial counts $2.81 \times 10^{8} \mathrm{CFU} / \mathrm{g}$ and Sikka recorded the lowest bacterial count of $1.97 \times 10^{8} \mathrm{CFU} / \mathrm{g}$.

\subsection{Identification \& Phylogeny}

The morphological and biochemical studies of the 35 isolates were performed according to (see Table 1). Molecular characterization was done using 16S rRNA gene sequencing. Nineteen (19) out of thirty five (35) isolates had $>99 \%$ similarity with known species. The isolates belongs to the phyla Firmicutes $(62.86 \%)$, followed by Proteobacteria (22.86\%) and Actinobacteria (14.29\%). The phylogenetic tree of the three different locations is as in (see Figure 2).

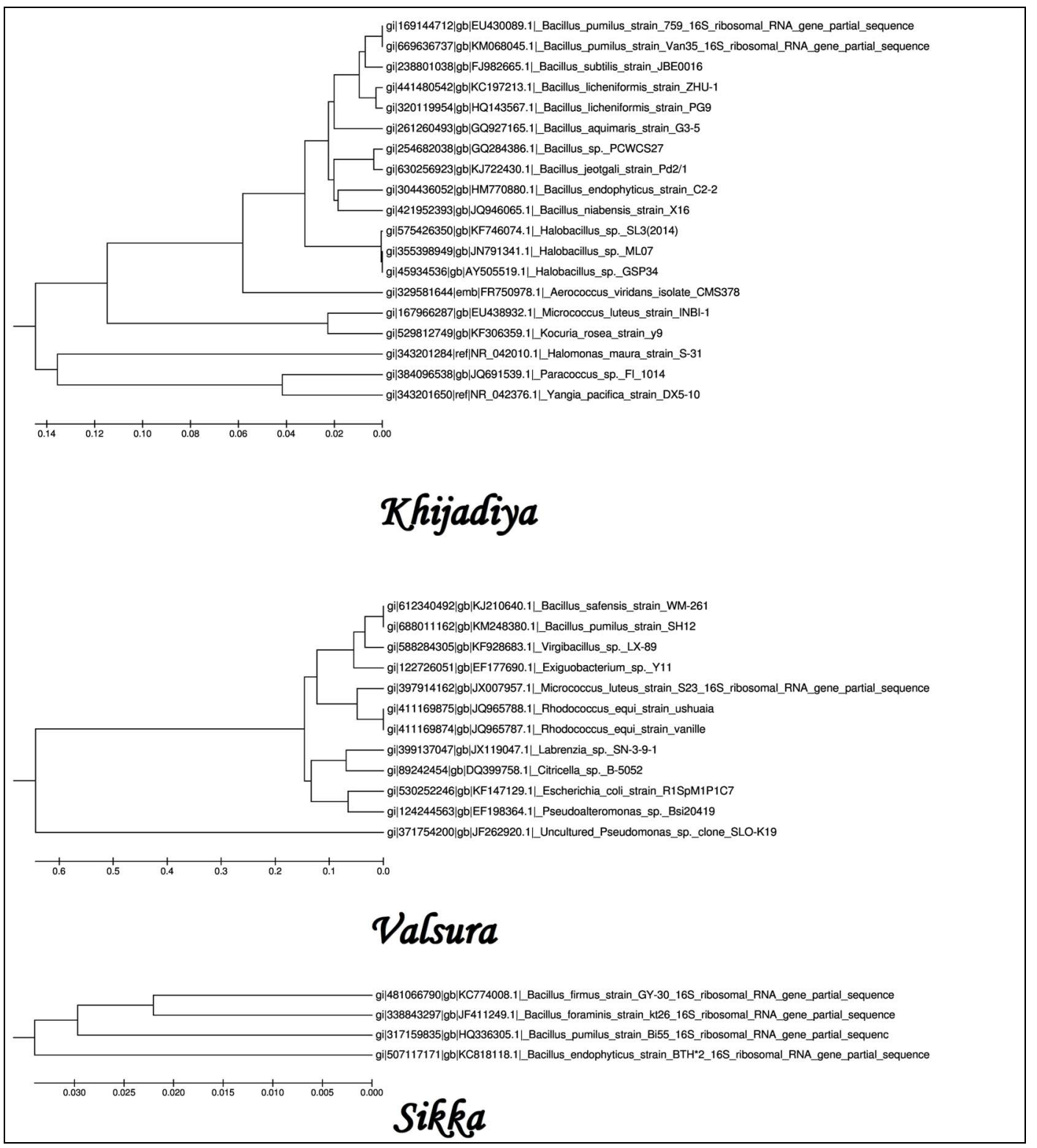

Figure 2. The phylogenetic tree indicates the phylogenetic relationship of the 35 isolates. 


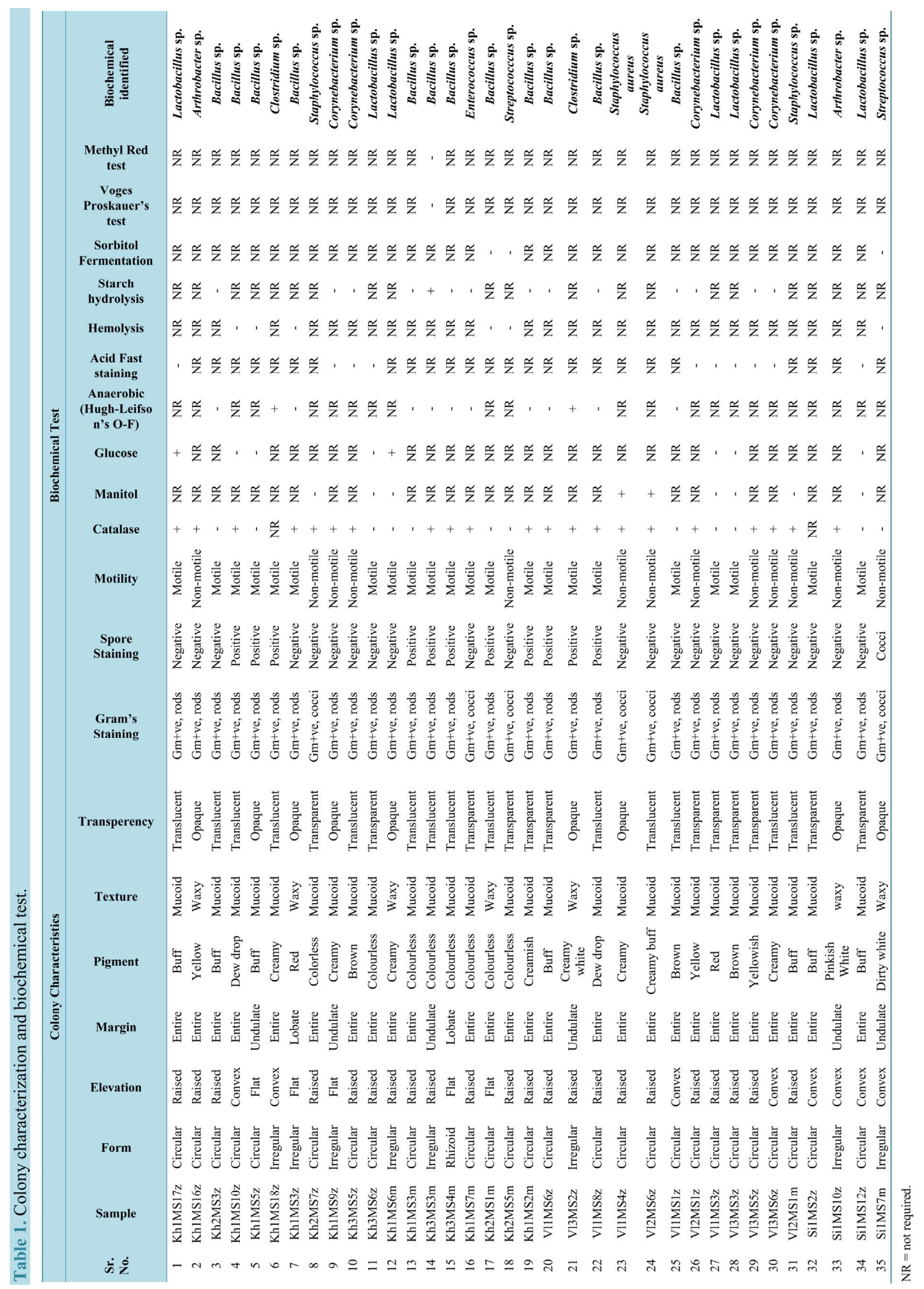




\subsection{Comparison of Classical and Conventional Identification Techniques}

Comparison of biochemical identification and molecular identification shows the similarities and dissimilarities in final identification of the organism shown in (see Table 2).

Table 2. Comparison of classical and conventional identification techniques.

\begin{tabular}{|c|c|c|c|c|c|}
\hline Sr. No. & Sample & Identified by $16 \mathrm{~S}$ rRNA gene sequencing & $\begin{array}{l}\text { \% Similarity in } \\
\text { alignment }\end{array}$ & Accession number & Identified by biochemical tests \\
\hline 1 & Kh1MS17z & Paracoccus sp. F1 1014 & 100 & JQ691539.1 & Lactobacillus sp. \\
\hline 2 & Kh1MS16z & Bacillus aquimaris strain G3-5 & 99 & GQ927165.1 & Arthrobacter sp. \\
\hline 3 & Kh2MS3z & Halobacillus sp. ML07 & 100 & JN791341.1 & Bacillus sp. \\
\hline 4 & Kh1MS10z & Bacillus endophyticus strain C2-2 & 99 & HM770880.1 & Bacillus sp. \\
\hline 5 & Kh1MS5z & Halomonas maura strain S-31 & 100 & NR_042010.1 & Bacillus sp. \\
\hline 6 & Kh1MS18z & Bacillus licheniformis strain PG9 & 99 & HQ143567.1 & Clostridium $s p$ \\
\hline 7 & Kh1MS3z & Bacillus niabensis strain $X 16$ & 99 & JQ946065.1 & Bacillus sp. \\
\hline 8 & $\mathrm{Kh} 2 \mathrm{MS} 7 \mathrm{z}$ & Bacillus licheniformis strain ZHU-1 & 99 & KC197213.1 & Staphylococcus sp. \\
\hline 9 & Kh1MS9z & Bacillus sp. PCWCS27 & 95 & GQ284386.1 & Corynebacterium sp. \\
\hline 10 & Kh3MS5z & Bacillus pumilus strain759 & 96 & EU430089.1 & Corynebacterium sp. \\
\hline 11 & Kh3MS6z & Bacillus pumilus strain Van35 & 97 & KM068045.1 & Lactobacillus sp. \\
\hline 12 & Kh1MS6m & Yangia pacifica strain: DX5-10 & 99 & NR_042376.1 & Lactobacillus sp. \\
\hline 13 & Kh1MS3m & Micrococcus luteus strain INBI-1 & 99 & EU438932.1 & Bacillus sp. \\
\hline 14 & Kh3MS3m & Bacillus subtilis strain JBE 0016 & 99 & FJ982665.1 & Bacillus sp. \\
\hline 15 & Kh3MS4m & Kocuria rosea strain Y9 & 99 & KF306359.1 & Bacillus sp. \\
\hline 16 & Kh1MS7m & Halobacillus sp. SL3(2014) & 99 & KF746074.1 & Enterococcus sp. \\
\hline 17 & Kh2MS1m & Bacillus jeotgali strain pd2/1 & 98 & KJ22430.1 & Bacillus sp. \\
\hline 18 & Kh2MS5m & Halobacillus sp. GSP34 & 99 & AY505519.1 & Streptococccus sp. \\
\hline 19 & Kh1MS2m & Aerococcus viridians isolate CMS378 & 90 & FR750978.1 & Bacillus sp. \\
\hline 20 & V11MS6z & Labrenzia sp. SN-3-9-1 & 99 & JX119047.1 & Bacillus sp. \\
\hline 21 & V13MS2z & Citreicella sp. B-5052 & 99 & DQ399758.1 & Clostridium sp. \\
\hline 22 & V11MS8z & Rhodococcus equi strain ushuaia & 99 & JQ965788.1 & Bacillus sp. \\
\hline 23 & V11MS4z & Escherichia coli strain R1SpM1 & 100 & KF147128.1 & Staphylococcus aureus \\
\hline 24 & V12MS6z & Rhodococcus equi strain vanille & 99 & JQ965787.1 & Staphylococcus aureus \\
\hline 25 & V11MS1z & Virgibacillus sp. $L X-89$ & 96 & KF928683.1 & Bacillus sp. \\
\hline 26 & V12MS1z & Bacillus safensis strain WM-261 & 97 & KJ210640.1 & Corynebacterium sp. \\
\hline 27 & V11MS3z & Bacillus pumilus strain $\mathrm{SH}-12$ & 98 & KM248380.1 & Lactobacillus sp. \\
\hline 28 & V13MS3z & Pseudoalteromonas sp. Bsi20419 & 98 & EF198364.1 & Lactobacillus sp. \\
\hline 29 & V13MS5z & $\begin{array}{l}\text { Uncultured Pseudomonas sp. Clone } \\
\text { SLO-K19 }\end{array}$ & 97 & JF262920.1 & Corynebacterium sp. \\
\hline 30 & V13MS6z & Micrococcus luteus strain S23 & 96 & JX007957.1 & Corynebacterium sp. \\
\hline 31 & V12MS1m & Exiguobacterium sp.Y11 & 99 & EF177690.1 & Staphylococcus sp. \\
\hline 32 & Si1MS2z & Bacillus firmus strain $G Y-30$ & 99 & KC774008.1 & Lactobacillus sp. \\
\hline 33 & Si1MS10z & Bacillus endophyticus strain BTH\#2 & 100 & KC818118.1 & Arthrobacter sp. \\
\hline 34 & SilMS12z & Bacillus pumilus strain Bi55 & 96 & HQ336305.1 & Lactobacillus sp. \\
\hline 35 & Si1MS7m & Bacillus foraminis strain kt26 & 99 & JF411249.1 & Streptococcus sp. \\
\hline
\end{tabular}




\section{Discussion}

The 35 culturable bacteria from three different locations of Avicennia marina were collected and studied for the representative diversity. The bacterial diversity as seen in Figure 2 shows that as the $\mathrm{pH}$ increases from 6.0 to 8.0 the diversity decreases. The family Bacillaceae $(60 \%)$ is the predominant family along all the three $\mathrm{pH}$ values and the existence of this family is found to be exclusive at higher $\mathrm{pH}$. The family Rhodobacteraceae constitutes 11.43\%; Micrococcaceae constitutes $8.57 \%$; and the families Nocardiaceae and Pseudoalteromonadaceae constitute 5.71\% (see Table 3). At pH 6.0 the diversity includes families like, Bacillaceae, Rhodobacteraceae,

Table 3. Taxonomic groups present in mangrove rhizosphere.

\begin{tabular}{|c|c|c|c|c|}
\hline Sr. No. & Sample & Identified by $16 \mathrm{~s} \mathrm{Sq}$. & Phylum & Family \\
\hline 1 & Kh1MS17z & Paracoccus sp. F1 1014 & Proteobacteria & Rhodobacteraceae \\
\hline 2 & Kh1MS16z & Bacillus aquimaris strain G3-5 & Firmicutes & Bacillaceae \\
\hline 3 & $\mathrm{Kh} 2 \mathrm{MS} 3 \mathrm{z}$ & Halobacillus sp. ML07 & Firmicutes & Bacillaceae \\
\hline 4 & Kh1MS10z & Bacillus endophyticus strain C2-2 & Firmicutes & Bacillaceae \\
\hline 5 & Kh1MS5z & Halomonas maura strain S-31 & Proteobacteria & Halomonadaceae \\
\hline 6 & Kh1MS18z & Bacillus licheniformis strain PG9 & Firmicutes & Bacillaceae \\
\hline 7 & Kh1MS3z & Bacillus niabensis strain $X 16$ & Firmicutes & Bacillaceae \\
\hline 8 & Kh2MS7z & Bacillus licheniformis strain ZHU-1 & Firmicutes & Bacillaceae \\
\hline 9 & Kh1MS9z & Bacillus sp. PCWCS27 & Firmicutes & Bacillaceae \\
\hline 10 & Kh3MS5z & Bacillus pumilus strain759 & Firmicutes & Bacillaceae \\
\hline 11 & Kh3MS6z & Bacillus pumilus strain Van35 & Firmicutes & Bacillaceae \\
\hline 12 & Kh1MS6m & Yangia pacifica strain: $D X 5-10$ & Proteobacteria & Rhodobacteraceae \\
\hline 13 & Kh1MS3m & Micrococcus luteus strain INBI-1 & Actinobacteria & Micrococcaceae \\
\hline 14 & Kh3MS3m & Bacillus subtilis strain JBE 0016 & Firmicutes & Bacillaceae \\
\hline 15 & Kh3MS4m & Kocuria rosea strain $Y 9$ & Actinobacteria & Micrococcaceae \\
\hline 16 & Kh1MS7m & Halobacillus sp. SL3 (2014) & Firmicutes & Bacillaceae \\
\hline 17 & Kh2MS1m & Bacillus jeotgali strain pd2/1 & Firmicutes & Bacillaceae \\
\hline 18 & Kh2MS5m & Halobacillus sp. GSP34 & Firmicutes & Bacillaceae \\
\hline 19 & Kh1MS2m & Aerococcus viridians isolate CMS378 & Firmicutes & Aerococcaceae \\
\hline 20 & V11MS6z & Labrenzia sp. SN-3-9-1 & Proteobacteria & Rhodobacteraceae \\
\hline 21 & V13MS2z & Citreicella sp. B-5052 & Proteobacteria & Rhodobacteraceae \\
\hline 22 & V11MS8z & Rhodococcus equi strain ushuaia & Actinobacteria & Nocardiaceae \\
\hline 23 & V11MS4z & Escherichia coli strain R1SpM1 & Proteobacteria & Enterobacteriaceae \\
\hline 24 & V12MS6z & Rhodococcus equi strain vanille & Actinobacteria & Nocardiaceae \\
\hline 25 & V11MS1z & Virgibacillus sp. LX-89 & Firmicutes & Bacillaceae \\
\hline 26 & V12MS1z & Bacillus safensis strain WM-261 & Firmicutes & Bacillaceae \\
\hline 27 & V11MS3z & Bacillus pumilus strain SH-12 & Firmicutes & Bacillaceae \\
\hline 28 & V13MS3z & Pseudoalteromonas sp. Bsi20419 & Proteobacteria & Pseudoalteromonadaceae \\
\hline 29 & V13MS5z & Uncultured Pseudomonas sp. Clone SLO-K19 & Proteobacteria & Pseudomonadaceae \\
\hline 30 & V13MS6z & Micrococcus luteus strain S23 & Actinobacteria & Micrococcaceae \\
\hline 31 & V12MS1m & Exiguobacterium sp. Y11 & Firmicutes & Bacillales Family XII. Incertae Sedis \\
\hline 32 & $\operatorname{Si} 1 \mathrm{MS} 2 \mathrm{z}$ & Bacillus firmus strain $G Y-30$ & Firmicutes & Bacillaceae \\
\hline 33 & Si1MS10z & Bacillus endophyticus strain BTH\#2 & Firmicutes & Bacillaceae \\
\hline 34 & Si1MS12z & Bacillus pumilus strain Bi55 & Firmicutes & Bacillaceae \\
\hline 35 & Si1MS7m & Bacillus foraminis strain kt26 & Firmicutes & Bacillaceae \\
\hline
\end{tabular}


Halomonadaceae, Micrococcaceae, Aerococcaceae; at pH 7.0 the diversity includes Bacillaceae, Rhodobacteraceae, Micrococcaceae, Nocardiaceae, Enterobacteriaceae, Pseduoalteromonadaceae, families and at $\mathrm{pH} 8.0$ the diversity is restricted to Bacillaceae family.

Bergy's Manual for determinative microbiology is an established key for identification of microbes. The key has successfully produced results which have shown $98 \%$ harmony with 16S rRNA sequencing when limited to a specific genus in case of marine microbes [13]. Also, in case of clinical samples like Mycobacteria and Vibrio, the biochemical identification shows a harmony in results making the score to $70 \%$ [14]. In another study working with 47 samples using biochemical tests and 16S rRNA gene PCR, in 33 cases (70.2\%), biochemical tests were confirmed by PCR [15]. In case of environmental samples, the samples are subjected to 16S rRNA gene sequencing, and biochemical tests of the genus are then used to confirm the genus and species identification [13]. In the current study unknown environmental samples were subjected to biochemical testing for the first stage of elimination, isolation and preservation. The identification of the isolated samples using 16S rRNA gene sequencing revealed a $51.43 \%$ match up to the phylum level, $48.57 \%$ up to class, $20 \%$ up to order and $17.14 \%$ up to family level. The match at genus level is at a low of $3 \%$. This shows that for environmental samples, where biochemical tests are an important tool for first stage identification, genus and species level identification can be confirmed by 16S rRNA gene sequencing. For 10 samples (28.57\%), namely, Kh1MS17z, Kh2MS3z, Kh1MS9z, Kh1MS7m, Kh1MS5m, V11MS6z, V13MS2z, V11MS1z, V13MS3z and V12MS1m, 16S rDNA gene sequencing could give an identification up to genus. Further determinative biochemical tests and MALDI-TOFF are needed to be applied to these samples. Biochemical tests and molecular techniques are complementary tools, and both are important for conclusive identification of unknown environmental samples. This diversity study has been able to cultivate an uncultured Pseudomonas sp. Clone SLO-K19, reported through 16S rRNA sequencing, on minimal media.

\section{Acknowledgements}

We acknowledge the initiation of this centre by Gujarat State biotechnology Mission [GSBTM], DST, GoG and the Department of Forest, Gujarat for providing the permission for sampling. The co author of the paper has no Conflict of Interest.

\section{References}

[1] Bhatt, S., Shah, D.G. and Desai, N. (2009) The Mangrove Diversity of Purna Estuary, South Gujarat, India. Tropical Ecology, 50, 287-293.

[2] Kathiresan, K. (2003a) How Do Mangrove Forests Induce Sedimentation? Revista de Biologia Tropical, 51, $355-360$.

[3] Tomlinson, P.B. (1986) The Botany of Mangroves. Cambridge Tropical Biology Series. Cambridge University Press, Cambridge.

[4] Saenger, P. (2002) Mangrove Ecology, Silviculture and Conservation. Kluwer Academic Publishers, Dordrecht, 11-18. http://dx.doi.org/10.1007/978-94-015-9962-7

[5] Kathiresan, K. (2003) Global Policies and Institution. Biodiversity in Mangrove Ecosystems. In: Kathiresan, K. and Subramanian, A.N., Eds., UNU-UNESCO International Training Course on Biodiversity in Mangrove Ecosystems, Course Manual, Annamalai University, India, 317-332.

[6] Anonymous (2005) State of Forest Report 2003. Forest Survey of India, Ministry of Environment and Forests, Dehradun.

[7] Brinda, V. and Mathew, A. (2012) Molecular Characterization and Identification of Unknown Bacteria from Waste Water. Indian Journal of Innovations and Developments, 1, 87-91.

[8] Pace, N.R. (1997) A Molecular View of Microbial Diversity and the Biosphere. Science, 272, 734-740. http://dx.doi.org/10.1126/science.276.5313.734

[9] Malik, S., Beer, M., Megharaj, M. and Naidu, R. (2008) The Use of Molecular Techniques to Characterize the Microbial Communities in Contaminated Soil and Water. Environment International, 34, 265-276. http://dx.doi.org/10.1016/j.envint.2007.09.001

[10] Schut, F., De-Vries, E.J., Gotitschal, J.C., Robertson, B.R., Harder, W., Prins, R.A. and Button, D.K. (1993) Isolation of Typical Marine Bacteria by Dilution Culture: Growth, Maintenance, and Characteristics of Isolates under Laboratory Conditions. Applied and Environmental Microbiology, 59, 2150-2160.

[11] Beisher, L. (1991) Microbiology in Practice, a Self Instructional Laboratory Course. Harper Collins Publishers, Inc., 
New York, 53-131.

[12] Thompson, J.D., Higgins, D.G. and Gibson, T.J. (1994) CLUSTAL W: Improving the Sensitivity of Progressive Multiple Sequence Alignment through Sequence Weighting, Position-Specific Gap Penalties and Weight Matrix Choice. Nucleic Acids Research, 22, 4673-4680. http://dx.doi.org/10.1093/nar/22.22.4673

[13] Nair, A.V., Vijayan, K.K. and Chakraborty, K. (2012) Diversity and Characterization of Antagonistic Bacteria from Tropical Estuarine Habitats of Cochin, India for Fish Health Management. World Journal for Microbiology and Biotechnology, 28, 2581-2592. http://dx.doi.org/10.1007/s11274-012-1067-5

[14] Shafipour, M., Ghane, M., Rahimi, A.S., Livani, S. and Ghaemi, E. (2014) The Comparison of Biochemical and Sequencing 16SrDNA Gene Methods to Identify Nontuberculous Mycobacteria. Archives of Razi Institute, 69, 137-142.

[15] Therese, K., Bartell, J., Deepa, P., Mangaiyarkarasi, S., Ward, D. and Dajcs, J. (2009) DNA Sequencing by Microseq Kit Targeting 16SrRNA Gene for Species Level Identification of Mycobacteria. Indian Journal of Medical Research, 129, 176-181. 